\title{
Pelatihan Excel (Pengelolaan Administrasi) Bagi Guru Sekolah Dasar Pada Korwilcam Kecamatan Ambarawa
}

\author{
Aries Setiawan ${ }^{* 1}$, Budi Widjajanto ${ }^{2}$, Ida Farida ${ }^{3}$ \\ ${ }^{1}$ Teknik Informatika Fakultas Ilmu Komputer Universitas Dian Nuswantoro, ${ }^{2}$ Sistem Informasi \\ Fakultas Ilmu Komputer Universitas Dian Nuswantoro, ${ }^{3}$ Manajemen Fakultas Ekonomi dan \\ Bisnis Universitas Dian Nuswantoro \\ E-mail: ${ }^{1}$ arissetya_005@dsn.dinus.ac.id,ㄹdpojok@gmail.com, ${ }^{3}$ ida.farida@dsn.dinus.ac.id
}

\begin{abstract}
Abstrak
Pengelolaan administrasi pada sekolah dasar menggunakan proses komputer akan mempermudah dari sisi pengarsipan, perhitungan serta penyediaan laporan. Tidak akan butuh waktu lama dalam menyediakan berkas yang sedang dicari. Hal ini juga berpengaruh terhadap layanan terhadap siswa dan orang tua siswa. Sejauh ini pemanfaatan komputer pada sekolah dasar hanya sebatas pada aktivitas pengetikan. Perlu pengembangan pada potensi guru-guru sekolah dasar di wilayah ini terutama dalam pengelolaan administrasi sekolah. Untuk itu perlu diberikan pembekalan mengenai pengelolaan administrasi dengan memanfaatkan Microsoft Excel. Pelatihan Excel (Pengelolaan Administrasi) Bagi Guru Sekolah Dasar Pada Korwilcam Kec. Ambarawa. Hasil akhir dari pelatihan ini adalah meningkatnya kemampuan yang dimiliki guru melalui pelatihan Excel pada materi pivot table, sehingga guru lebih lancar dalam mengelola administrasi. Perhitungan yang otomatis yang disajikan juga mampu mengefektifkan kinerja guru dalam merekap administrasi keuangan, selain itu mampu mengefisienkan waktu pembuatan.
\end{abstract}

Kata kunci: Excel, Administrasi, Sekolah Dasar, Ambarawa

\begin{abstract}
Administrative management in primary schools using computer processes will facilitate the archiving, calculation and report provision. It won't take long to provide the file that is being searched for. This also affects services to students and parents of students. So far the use of computers in elementary schools is only limited to typing activities. Need to develop the potential of elementary school teachers in this region, especially in the management of school administration. For this reason, it is necessary to provide a briefing on administrative management using Microsoft Excel. Excel (Administrative Management) Training For Elementary School Teachers At Korwilcam Kec. Ambarawa Increased skills needed by teachers through Excel training in pivot material tables, so that teachers are more efficient in managing administration. Automatic assessments presented are also able to streamline teacher performance in recapitalizing financial administration, in addition to being able to streamline manufacturing time.
\end{abstract}

Keywords: Excel, Administration, Elementary School, Ambarawa 


\section{PENDAHULUAN}

Microsoft Excel mampu membantu menyelesaikan permasalahan pengelolaan administrasi yang berkaitan dengan operasi speadsheet atau masalah perhitungan angka [1]. Semua pengelolaan administrasi baik pada organisasi, instansi sampai dengan perorangan dapat secara praktis dikelola dengan pemanfaatan rumus perhitungan yang disediakan oleh Microsoft Excel [2].

Pada lingkungan sekolah dasar, aktivitas pengelolaan administrasi meliputi pengelolaan data peserta didik, pengelolaan nilai raport, pengelolaan data statistika dan fungsi kependidikan lainnya [3]. Selama ini pengelolaan administrasi pada sekolah dasar masih banyak menggunakan sarana manual seperti buku dan whitebox. Perlu ada peningkatan mutu pengelolaan dari manual ke dalam proses komputerisasi.

Pengelolaan administrasi pada sekolah dasar menggunakan proses komputer akan mempermudah dari sisi pengarsipan, perhitungan serta penyediaan laporan [4]. Tidak akan butuh waktu lama dalam menyediakan berkas yang sedang dicari. Hal ini juga berpengaruh terhadap layanan terhadap siswa dan orang tua siswa [5].

Sejauh ini pemanfaatan komputer pada sekolah dasar hanya sebatas pada aktivitas pengetikan. Perlu pengembangan pada potensi guru-guru sekolah dasar di wilayah ini terutama dalam pengelolaan administrasi sekolah. Untuk itu perlu diberikan pembekalan mengenai pengelolaan administrasi dengan memanfaatkan Microsoft Excel.

Pada penelitian sebelumnya, pemanfaataan Ms Excel mampu meningkatkan tingkatan berfikir dan kreasi pengguna dalam melakukan pemecahan masalah matematik, selain itu Ms Excel mampu menunjang prestasi dan motivasi belajar [6].

Pelatihan yang ada yaitu tentang pivot table, materi ini menjelaskan kemampuan meringkas dari sejumlah data yang mempunyai jumlah banyak dan sangat bervariatif yang sulit untuk dilakukan peringkasan secara manual [7]. Pivot juga menyajikan analisa dari sejumlah data sehingga user akan lebih menyimpulkan dari sejumlah data analisis yang dihasilkan [8].

Melalui pelatihan ini guru sekolah dasar akan memudahkan dalam mengelola administrasi sekolah dengan bantuan Microsoft Excel serta mampu mengatasi penyediaan laporan yang mungkin selama ini sering terlambat akibat pengelolaan yang masih manual.

\section{METODE PELAKSANAAN DAN PENYAMPAIAN}

Metode pelaksanaan pengabdian masyarakat melalui pelatihan yaitu dengan praktek langsung menggunakan laptop yang dibawa dari rumah untuk kemudian pengerjaan latihanlatihan Microsoft Excel untuk memperkuat pemahaman para guru. Tahapan detail, pelaksanaan kegiatan pengabdian ini meliputi:

1. Melakukan koordinasi dengan Korwilcam Kec. Ambarawa sebagai pengurus guruguru sekolah dasar di wilayahya

2. Menentukan tempat dan waktu penyelenggaran pelatihan.

3. Membuat rundown acara disesuaikan jadwal dan ketersediaan jadwal para guru.

4. Membuat undangan dan menyampaikan pemberitahuan kepada mitra. Informasi yang terkandung meliputi: tempat dan waktu pelaksanaan, serta agenda kegiatan.

5. Menyiapkan LCD dan sarana prasarana kegiatan.

6. Melakukan pengarsipan kegiatan dan pengarsipan laporannya.

7. Administrasi yang meliputi undangan peserta, surat menyurat, dokumentasi, daftar hadir untuk diarsip dan untuk pembuatan pelaporan.

Metode dan peran yang dilakukan oleh penulis dalam penyampaian materi adalah sebagai berikut:

1. Menjelaskan penerapan Microsoft Excel bagi kegiatan guru sekolah dasar

2. Menjelaskan lingkungan Microsoft Excel

3. Menjelaskan fungsi-fungsi yang pada Microsoft Excel 
4. Menjelaskan pivot, langkah mudah membuat laporan dengan Microsoft Excel.

\section{HASIL DAN PEMBAHASAN}

3.1 Materi

Materi yang diberikan meliputi fungsi statistic dengan pivot meliputi perhitungan jumlah data, perhitungan data dengan jumlah tertentu. Pivot Table berfungsi untuk meringkas, menganalisa, meng-explore, serta menyajikan table [7]. Dengan pivot tabel akan cepat untuk dibuat dengan beberapa data dalam tabel menggunakan berbagai rumus excel (Excel Formula) [8].

\begin{tabular}{|c|c|c|c|c|c|c|c|c|c|c|c|c|c|c|c|c|c|}
\hline & B & C & D & E & $\mathrm{F}$ & G & H & 1 & J & k & L & M & N & 0 & p & Q & $R$ \\
\hline \multicolumn{18}{|c|}{1 TRANSAKSI PENGADAAN BUKU } \\
\hline \multicolumn{18}{|c|}{\begin{tabular}{l|l|l|l|}
2 & & & \\
\end{tabular}} \\
\hline & & & KODE & & & & & & & & JML & & KODE & & BIAYA & & \\
\hline 3 & NO. $\mathrm{T}$ & TANGGAL & BUKU & JENIS BUKU & PENGARANG & PENERBIT & HARGA & BULAN & TAHUN JU & JMLAH & HARGA & SEMESTER & PENGIRIM & NAMA PENGIRIM & A KIRIM & TOTAL & POTONGAN \\
\hline 4 & 1 & 1-Jan-20 & & MATEMATIKA & DRS. ANDI YUSUF & PT. ERLANGGA & & DO JANUARI & 2020 & 50 & 502250000 & GENAP & P1 & JNE & 150000 & 02400000 & $0 \quad 24000$ \\
\hline 5 & 2 & 12-Jul-18 & & BAHASA INDONESIA & DRA. SUPRIYADI & PT. TIGA SERANGKAI & & $00 \mathrm{JULI}$ & 2018 & 45 & 151575000 & 0 GANIL & P2 & JNT & 200000 & 017775000 & 17750 \\
\hline 6 & 3 & 13-Jul-18 & & IPA & DRS. HIMAWAN & PT. CERAH & & $00 \mathrm{JULI}$ & 2018 & 40 & 102200000 & O GANJIL & P3 & POS INDONESIA & 180000 & $0 \quad 2380000$ & 23800 \\
\hline 7 & 4 & 14-Jan-20 & & IPS & ANDIKA, S.PD & PT. TIGA SERANGKAI & & 00 JANUARI & 2020 & & 112460000 & 0 GENAP & P3 & POS INDONESIA & 180000 & 02640000 & 26400 \\
\hline 8 & 5 & $15-\tan -20$ & BO5 & BAHASA JAWA & FAHRI, S.PD & PT. ERLANGGA & & DO JANUARI & 2020 & 55 & 552750000 & 0 GENAP & P2 & JNT & 200000 & 02950000 & 29500 \\
\hline 9 & 6 & 16-Jan-20 & & PENDIDIKAN JASMANI & DRS. FRIMANDI & PT. TIGA SERANGKAI & & DO JANUARI & 2020 & 43 & 131720000 & 0 GENAP & P1 & JNE & 150000 & $\begin{array}{ll}0 & 1870000\end{array}$ & 18700 \\
\hline 10 & 7 & 17-Jan-20 & & PAl & DRS. RAHMAN & PT. ERLANGGA & 5600 & 00 JANUARI & 2020 & 46 & 162576000 & 0 GENAP & P2 & JNT & 200000 & $0 \quad 2776000$ & 27760 \\
\hline 11 & 8 & 12-Jul-19 & & TEMATIK 1 & DRA. YULKIFLI & PT. CERAH & 4300 & $00 \mathrm{JULI}$ & 2019 & 44 & H4 1892000 & O GANJIL & P2 & JNT & 200000 & 02092000 & 20920 \\
\hline 12 & 9 & 13-Jul-19 & & TEMATIK 2 & NUR INDAH, S.PD & PT. TIGA SERANGKAI & 4200 & $00 \mathrm{JULI}$ & 2019 & 42 & 121764000 & O GANILL & P1 & JNE & 150000 & 01914000 & 19140 \\
\hline 13 & 10 & 14-Jul-19 & & PENDIDIKAN PANCASILA & YAHYA HALIM, S.PD & PT. ERLANGGA & 3900 & $00 \mathrm{JULI}$ & 2019 & 40 & 101560000 & O GANILL & P1 & JNE & 150000 & $\begin{array}{ll}0 & 1710000\end{array}$ & 17100 \\
\hline 14 & 11 & 15-Jul-19 & & TEMATIK 2 & NUR INDAH, S.PD & PT. TIGA SERANGKAI & 4200 & $00 \mathrm{JULI}$ & 2019 & 35 & 351470000 & O GANILL & P3 & POS INDONESIA & 180000 & 01650000 & 16500 \\
\hline 15 & 12 & 16-Jul-19 & & TEMATIK1 & DRA. YULKIFLI & PT. CERAH & 4300 & $00 \mathrm{JULI}$ & 2019 & 54 & 342322000 & O GANJIL & P3 & POS INDONESIA & 180000 & $0 \quad 2502000$ & 25020 \\
\hline 16 & 13 & 17-Jul-19 & & PAI & DRS. RAHMAN & PT. ERLANGGA & 5600 & DO JULI & 2019 & 46 & 162576000 & O GANIL & P3 & POS INDONESIA & 180000 & 02756000 & 27560 \\
\hline 17 & 14 & 16-Jan-20 & & PENDIDIKAN JASMANI & DRS. FRIMANDI & PT. TIGA SERANGKAI & 4000 & 00 JANUARI & 2020 & 4 & 141760000 & O GENAP & P1 & JNE & 150000 & $\begin{array}{ll}0 & 1910000\end{array}$ & 19100 \\
\hline 18 & 15 & 17- $\operatorname{Jan}-20$ & & BAHASA JAWA & FAHRI, S.PD & PT. ERLANGGA & 5000 & DO JANUARI & 2020 & 40 & 102000000 & O GENAP & $P 2$ & JNT & 200000 & $0 \quad 2200000$ & 22000 \\
\hline 19 & 16 & 18-Jan-20 & BO2 & BAHASA INDONESIA & DRA. SUPRIYADI & PT. TIGA SERANGKAI & 3500 & DO JANUARI & 2020 & 45 & 151575000 & 0 GENAP & P2 & JNT & 200000 & $\begin{array}{ll}0 & 1775000\end{array}$ & 17750 \\
\hline 20 & 17 & 19-Jan-20 & & IPA & DRS. HIMAWAN & PT. CERAH & 5500 & 00 JANUARI & 2020 & 42. & 122310000 & O GENAP & P1 & JNE & 150000 & 02460000 & 24600 \\
\hline 21 & 18 & 20-Jan-20 & & IPS & ANDIKA, S.PD & PT. TIGA SERANGKAI & 6000 & 00 JANUARI & 2020 & 43 & 132580000 & O GENAP & P1 & JNE & 150000 & $\begin{array}{ll}0 \quad 2730000 \\
\end{array}$ & 27300 \\
\hline 22 & 19 & 16-Jul-19 & & MATEMATIKA & DRS. ANDI YUSUF & PT. ERLANGGA & 4500 & DO JULI & 2019 & 42. & 121890000 & O GANILL & P2 & JNT & 200000 & 02090000 & 20900 \\
\hline 23 & 20 & 17-Jul-19 & BO4 & IPS & ANDIKA, S.PD & PT. TIGA SERANGKAI & 6000 & $00 \mathrm{JULI}$ & 2019 & 50 & 503000000 & O GANJIL & P2 & JNT & 200000 & $0 \quad 3200000$ & 32000 \\
\hline
\end{tabular}

\section{Gambar 1. Pivot Tabel}

Dengan pivot pemakai dengan mudah menyesuaiakan tampilan data yang. Beberapa pengolahan hasil pivot adalah sebagai berikut

1. Menampilkan rangkuman data dengan filter berdasarkan penerbit 


\begin{tabular}{|c|c|c|c|c|c|c|c|c|}
\hline 4 & A & B & $\mathrm{C}$ & D & $E$ & $\mathrm{~F}$ & G & H \\
\hline 1 & PENERBIT & PT. CERAH & & & & & & \\
\hline \multicolumn{9}{|l|}{2} \\
\hline 3 & Sum of JUMLAH & Column Labels $\nabla$ & & & & & & \\
\hline 4 & Row Labels $\nabla$ & \multicolumn{4}{|c|}{201820192020 Grand Total } & & & \\
\hline 5 & $\Theta_{\text {B03 }}$ & 40 & & 42 & 82 & & & \\
\hline 6 & IPA & 40 & & 42 & 82 & & & \\
\hline 7 & $\boxminus \mathrm{B} 08$ & & 98 & & 98 & & & \\
\hline 8 & TEMATIK 1 & & 98 & & 98 & & & \\
\hline 9 & Grand Total & 40 & 98 & 42 & 180 & & & \\
\hline
\end{tabular}

Gambar 2. Pivot Tabel 2

dari hasil pivot table diatas dapat disimpulkan bahwa untuk jenis buku yang dikarang oleh PT.Cerah pada tahun 2018 sejumlah 40, dan tahun 2020 sejumlah 42 dn total buku IPA ada 82 buah. Begitu juga pada buku jenis Tematik yang diterbitkan oleh PT. Cerah pada tahub 2019 ada sejumlah 98.

Total buku yang diterbitkan oleh PT, Cerah pada tahun 2018 ada 40, tahun 2019 ada 98 buku dan 2020 ada 42 buku .

2.Menampilkan rangkuman data dengan filter berdasarkan pengarang

\begin{tabular}{|c|c|c|c|c|c|c|c|c|c|}
\hline 4 & $A$ & B & C & D & $E$ & $\mathrm{~F}$ & G & H & I \\
\hline 1 & PENGARANG & DRA. SUPRIYADI $\nabla$ & & & & & & & \\
\hline 2 & & & & & & & & & \\
\hline 3 & & Values & & & & & & & \\
\hline 4 & Row Labels & Sum of TAHUN & Sum of JUMLAH & & & & & & \\
\hline 5 & $\because$ BAHASA INDONESIA & 4038 & 90 & & & & & & \\
\hline 6 & GANJIL & 2018 & 45 & & & & & & \\
\hline 7 & GENAP & 2020 & 45 & & & & & & \\
\hline 8 & Grand Total & 4038 & 90 & & & & & & \\
\hline 9 & & & & & & & & & \\
\hline
\end{tabular}

Gambar 3. Tampilan rangkuman data dengan filter

dari hasil pivot table diatas dapat disimpulkan bahwa buku bahasa Indonesia yang di karang oleh Dra. Supriyadi pada semester ganjil tahun 2018 ada 45 buah dan pada semetsre genap 2020 ada 45 buah.

3.Menampilkan rangkuman data dengan filter berdasarkan pengarang beserta tampilan grafik 


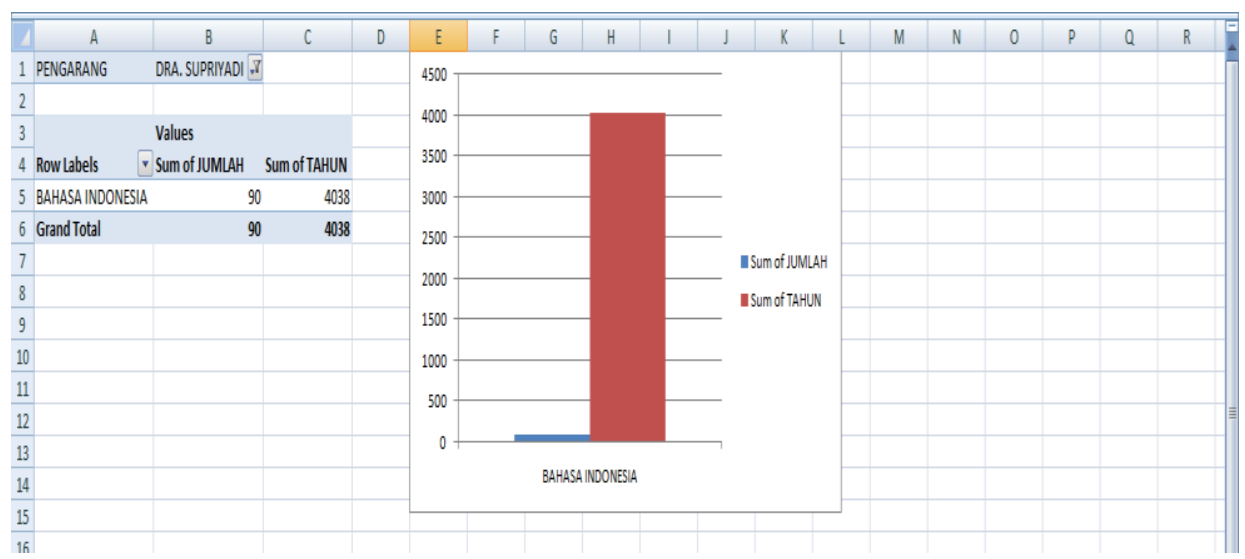

Gambar 4. Rangkuman data dengan filter berdasarkan pengarang

Grafik juga akan mudah disajikan untuk membantu analisa user terhadap sejumlah data, karena selain berupa data ringkasan analisis, user juga lebih mudah dalam pembacaan analisa melalui tampilan grafik.

\subsection{Pelaksanaan}

Dari evaluasi pelaksanaan praktek di tempat mitra, dihasilkan perbandingan hasil seperti berikut :

Tabel 1. Hasil Perbandingan

\begin{tabular}{|c|c|c|}
\hline Item Pembanding & $\begin{array}{c}\text { Sebelum Pemakaian } \\
\text { Pivot }\end{array}$ & Setelah Pemakaian Pivot \\
\hline Waktu & Lebih dari 20 menit & Kurang dari 3 menit \\
\hline Ketelitian & $\begin{array}{c}\text { Tergantung ketelitian } \\
\text { user }\end{array}$ & Secara otomatis dari aplikasi \\
\hline Tingkat Efektif & $\begin{array}{c}\text { Laporan kurang efektif } \\
\text { dan terlalu panjang }\end{array}$ & $\begin{array}{c}\text { Sangat efektif untuk fungsi } \\
\text { peringkasan laporan }\end{array}$ \\
\hline
\end{tabular}

Dari sisi waktu pemakaian pivot table jauh lebih efektif dari sebalumnya, ketelitian hasil analisa jauh lebih baik karena system Excel secara otomatis mampu menampilkan hasil lebih detail walaupun dengan kapasitas data yang sangat besar, sehingga user tidak perlu berfikir lama untuk menganalisa dan mengambil keputusan.

\section{KESIMPULAN}

Hasil akhir dari pelatihan ini adalah sebagai berikut :

1. Meningkatnya kemampuan yang dimiliki guru melalui pelatihan Excel pada materi pivot table, sehingga guru lebih lancar dalam mengelola administrasi. Perhitungan yang otomatis yang disajikan juga mampu mengefektifkan kinerja guru dalam merekap administrasi keuangan, selain itu mampu mengefisienkan waktu pembuatan.

2. Pembuatan laporan dan rangkuman perhitungan dapat mudah didapatkan dengan melakukan operasi pivot untuk selanjutnya dapat dijadikan referensi pengambilan keputusan

\section{SARAN}

Materi pelatihan perlu dipraktekkan oleh peserta (guru sekolah dasar) perlu diimplementasikan dalam aktivitas pembuatan administrasi sehari-hari guna mendukung hasil perhitungan. 


\section{DAFTAR PUSTAKA}

[1] Ambyah Harjanto, "Pelatihan Pemanfaatan Microsoft Office Excel Untuk Pengolahan Nilai Bagi Guru Sd Negeri 1 Tanjung Seneng Bandar Lampung Tahun 2019," Jurnal Adiguna, vol. 4, pp. 3235, 2019.

[2] Putu Asti Lestari, "Pelatihan Aplikasi Perkantoran Menggunakan Microsoft Office Di Panti Asuhan Rumah Impian Kota Denpasar," Jurnal Lentera Widya, vol. 1, pp. 30-34, Desember 2019.

[3] "Pelatihan Microsoft Excel Untuk Meningkatkan Kompetensi Guru-Guru Di Kabupaten Banyuasin," Seminar Nasional Pengabdian Masyarakat, pp. 349-355, Desember 2019.

[4] Asti Riani Putri, "Optimalisasi Penggunaan Microsoft Excel Untuk Pengolahan Nilai Raport Di Sman 1 Ngunut Tulungagung," J-Adimas, vol. 3, pp. 1-5, Juli 2015.

[5] Petro San, "Pelatihan Microsoft Excel Sebagai Penunjang Ketrampilan Hard Skill Bagi Siswa Pada SMK YPSEI Palangka Raya," Jurnal Abdimas BSI, vol. 2, pp. 280-286, Agustus 2019.

[6] Martiningsih , "Efektivitas Pemanfaatan Ms Excel Dalam Pembelajaran Matematika Di Smp Muhammadiyah 1 Surabaya," pp. 107-120.

[7] Nova Eka Diana, "Evaluasi Pelatihan Pivot Tabel Untuk Analisis Worksheet Data Bag Pelajar MAN 21 Jakarta," Jurnal Widya Laksana, vol. 8, pp. 113-118, Agustus 2019.

[8] Subagyo, "Manfaat Fitur "Pivottable" Dari Microsoft Office Excel Untuk Pengolahan Data Statistik Perpustakaan," Jurnal Pustakawan Indonesia, vol. 10, pp. 14-22, 2019.

\section{UCAPAN TERIMA KASIH}

Terima kasih kepada Lembaga Penelitian dan Pengabdian Masyarakat Universitas Dian Nuswantoro yang telah memberikan pendanaan pada program kemitraan masyarakat ini

\section{LAMPIRAN KEGIATAN}
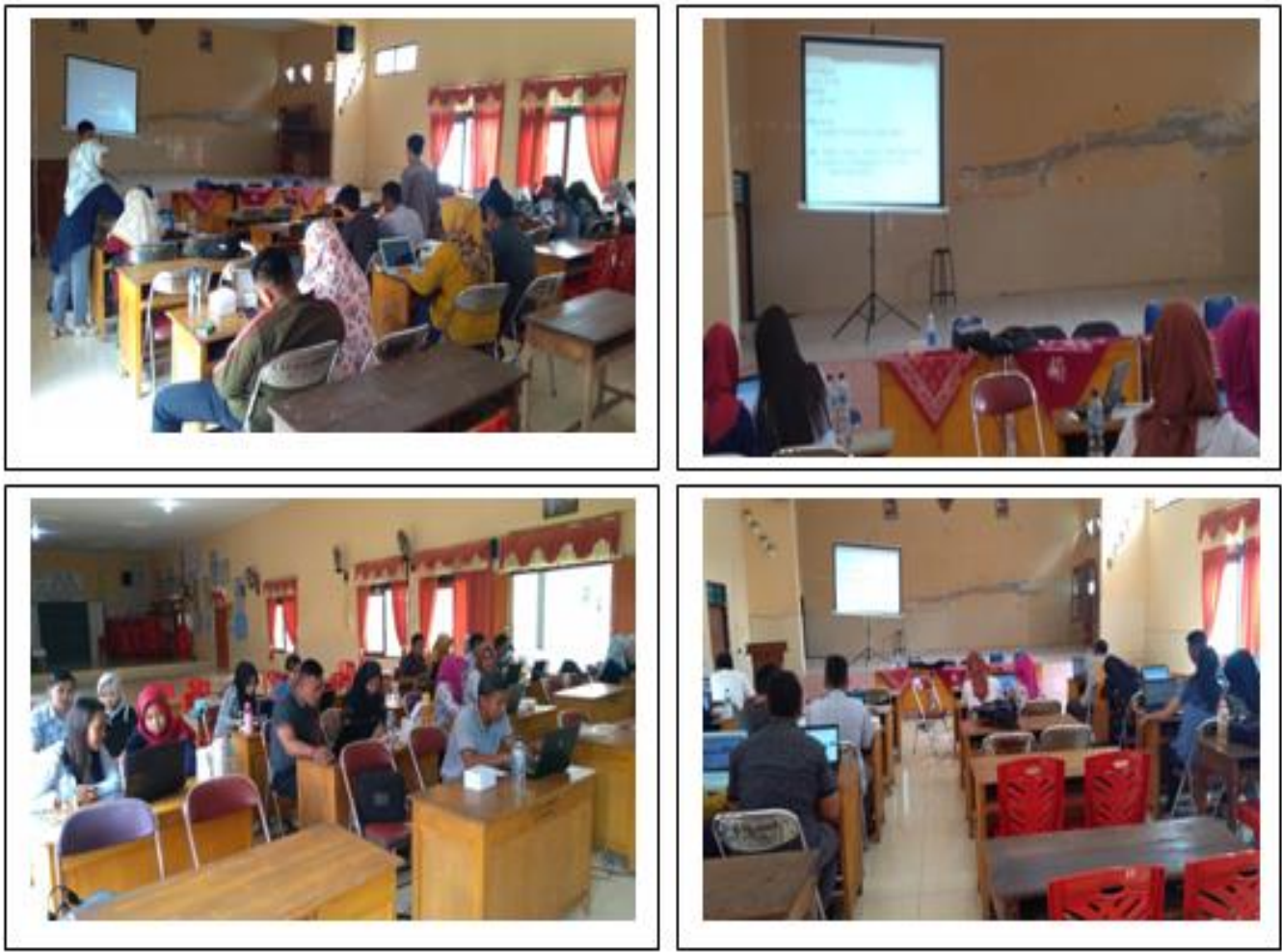